\title{
TEKNIK PENGOLAHAN SKOR HASIL EVALUASI
}

Wulan Suci Ramadhani ${ }^{1}$, Murti Murti ${ }^{2}$, Muhammad Arsyam ${ }^{3}$

\footnotetext{
${ }^{1}$ Sekolah Tinggi Agama Islam (STAI) Darud Dakwah Wal-Irsyad (DDI) Kota Makassar, Indonesia

Email: ramadhaniwulan038@gmail.com

${ }^{2}$ Sekolah Tinggi Agama Islam (STAI) Darud Dakwah Wal-Irsyad (DDI) Kota Makassar, Indonesia

Email: murtiabdullah087@gmail.com

${ }^{3}$ Sekolah Tinggi Agama Islam (STAI) Darud Dakwah Wal-Irsyad (DDI) Kota Makassar, Indonesia

Email: arsyam0505@gmail.com
}

\begin{abstract}
ABSTRAK
Proses pendidikan terjadi dengan tujuan yang beragam. Masing-masing negara memiliki titik tekan sendiri dalam tujuan pendidikan yang ingin di capai. Tujuan pendidikan di negara maju dan berkembang adalah berbeda. Bahkan, antar negara maju dan berkembang itu sendiri tujuan pendidikannya tidak sama. Begitu juga tujuan pendidikan di daerah dan perkotaan dan pedesaan adalah berbeda. Tidak ada tujuan pendidikan di suatu negara atau wilayah sama persis di negara atau wilayah lain. Namun, ini tidak berarti tidak ada unsur-unsur yang sama dalam tujuan pendidikan di antara semua negara atau bangsa di permukaan bumi ini.
\end{abstract}

Kata Kunci: Teknik, Pengolahan Skor, Hasil Evaluasi

\section{A. PENDAHULUAN}

Evaluasi pembelajaran merupakan bagian penting dalam proses belajar mengajar, hal ini menjadi penting sebab dengan adanya evaluasi dapat mengetahui kelemahan-kelemahan dan kekurangan serta perkembangan proses belajar mengajar dan masih banyak hal lain yang berhubungan dengan pentingnya dan tujuan evaluasi. Dapat dikatakan bahwa semakin baik atau semakin buruknya sebuah pembelajaran sangat ditentukan oleh proses pengevaluasiannya.

Kebanyakan pengajar tidak begitu memperdulikan teknik-teknik yang baik dalam menyelenggarakan suatu instrumen dan ilmu-ilmu yang ada dalam evaluasi pembelajaran. Dalam evaluasi pembelajaran terdapat teknik-teknik pelaksanaan suatu instrumen, macam-macamnya, pemilihan soal-soal yang baik, cara penskoran, pengolahannya dan lain sebagainya.

Patut untuk diperhatikaan oleh para pengajar tentang pentingnya menguasai ilmu pengolahan hasil evaluasi. Dengan ilmu ini maka tidak dikhawatirkan terjadi ketidak adilan dalam pemberian nilai pada peserta didik. 


\section{B. PEMBAHASAN}

\section{Teknik Pengolahan Data Hasil Evaluasi}

Banyak guru yang sudah mengumpulkan data hasil tes dari peserta didiknya, tetapi tidak memperhatikan cara mengolahnya sehingga data tersebut menjadi mubazir (data tanpa makna). Sebaliknya, jika hanya ada data yang relative sedikit, tetapi sudah mengetahui cara pengolahannya, maka data tersebut akan mempunyai makna. Pada umumnya, pengolahan data hasil tes menggunakan bantuan statistic. Analisis statistic digunakan jika ada data kuantitatif, yaitu data-data yang berbentuk angka, sedangkan untuk data kualitatif, yaitu data yang berbentuk kata-kata, tidak dapat diolah dengan statistic.

Menurut Zainal Arifin (2006) dalam mengolah data hasil tes, ada empat langkah pokok yang harus ditempuh. Pertama, menskor, yaitu member skor pada hasil tes yang dapat dicapai oleh peserta didik. Untuk memperoleh skor mentah diperlukan tiga jenis alat bantu, yaitu kunci jawaban, kunci scoring, dan pedoman konversi. Kedua, mengubah skor mentah menjadi skor standart sesuai dengan norma tertentu. Ketiga, mengkonversikan skor standart kedalam nilai, baik dalam bentuk huruf ataupun angka. Keempat, melakukan alalisis soal (jika diperlukan) untuk mengetahui derajat validitas dan reliabilitas soal, tingkat kesukaran soal, dan daya pembeda.

Bila semua jawaban siswa dalam suatu tes sudah diperiksa dan diberikan skor, maka kita akan memperoleh skor akhir untuk setiap siswa. Skor inilah yang disebut dengan skor mentah. Kegiatan ini harus dilakukan dengan ekstra hati-hati karena menjadi dasar bagi pengolahan hasil tes menjadi nilai prestasi. Kita tidak dapat menjadikan skor mentah ini sebagai nilai akhir untuk siswa, kita harus mengubah dan mengolahnya terlebih dahulu menjadi skor terjabar. Dalam mengolah skor mentah (raw score) menjadi nilai huruf dan skor standart dengan urutan uraian sebagai berikut:[3]

a. Mengolah skor mentah menjadi nilai huruf

b. Mengolah skor mentah menjadi skor standart 1-10

c. Mengolah skor mentah menjadi skor standart Z dan T 


\section{Penilaian Acuan Patokan (PAP)}

a. Pengolahan Skor Mentah Menjadi Nilai Huruf

Sebelum membahas pengelolaan skor kita buat perumpamaan terlebih dahulu. Terdapat 60 item soal pilihan ganda pelajaran bahasa Arab, tiap item yang benar berbobot 1. Skor mentah yang diperoleh 20 siswa adalah 32, 36, 27, 50, 22, 34, 35, 37, 43, 17, 21, 42, 46, 32, 31, 28, 57, $57,54,51$.

Prosedur yang dapat ditempuh adalah sebagai berikut:

a) skor ideal, yaitu skor yang mungkin dicapai jika semua item dapat dijawab dengan benar. Skor ideal diperoleh dengan jalan menghitung jumlah item yang diberikan serta bobot dari tiap-tiap item.

Dari contoh diatas diketahui skor idealnya adalah 60

b) Mencari rata-rata ideal (id) dengan rumus:

$=1 / 2 \times$ skor ideal $=1 / 2 \times 60=30$

c) Mencari deviasi (SD) ideal dengan cara:

$\mathrm{SD}=1 / 3 \times \mathrm{SD}=1 / 3 \times 30=10$

d) Menyusun kebutuhan konversi sesuai dengan yang dibutuhkan.

Adapun pedoman konversi dengan adalah:

$+1,5(\mathrm{SD})=30+1,5 \times 10=45=\mathrm{A}$

$+0,5(\mathrm{SD}) \quad=30+0,5 \times 10=35=\mathrm{B}$

$-0,5(\mathrm{SD}) \quad=30-0,5 \times 10=25=\mathrm{C}$

- $1,5(\mathrm{SD})=30-1,5 \times 10=15=\mathrm{D}$

Daridata tersebut dapat kita simpulkan bahwa siswa yang mendapat skor 45 - 60 mendapat nilai A, $35-44=\mathrm{B}, 25-34=\mathrm{C}, 15-24=\mathrm{D}, 0-14=\mathrm{E}$.

Pemberiannilai dengan menggunakan huruf disesuaikan dengan huruf yang terdapat dalam urutan abjad. Huruf tidak hanya menunjukkan kuantitas, tetapi dapat juga digunakan sebagai simbol untuk menggambar kualitas.

\begin{tabular}{|c|c|c|}
\hline Skor Angka & Nilai Huruf & Predikat \\
\hline 50 & A & Sangat Baik \\
\hline 37 & B & Baik \\
\hline 33 & C & Cukup \\
\hline 22 & D & Kurang \\
\hline 5 & E & Sangat Kurang \\
\hline
\end{tabular}


b. Skor mentah menjadi skor standar $1-10$

Untukmengubah skor mentah menjadi skor terjabar dalam skala 1 - 10 dapat digunakan ketentuan-ketentuan berikut:

$+2,25(\mathrm{SD})=10=30+2,25 \times 10=53=10$

$+1,75(\mathrm{SD})=9=30+1,75 \times 10=48=9$

$+1,25(\mathrm{SD})=8=30+1,25 \times 10=43=8$

$+0,75(\mathrm{SD})=7=30+0,75 \times 10=38=7$

$+0,25(\mathrm{SD})=6=30+0,25 \times 10=33=6$

$-0,25(\mathrm{SD})=5 \quad=30-0,25 \times 10=28=5$

$-0,75(\mathrm{SD})=4=30-0,75 \times 10=23=4$

$-1,25(\mathrm{SD})=3=30-1,25 \times 10=18=3$

$-1,75(\mathrm{SD})=2=30-1,75 \times 10=13=2$

$-2,25(\mathrm{SD})=1=30-2,25 \times 10=8=1$

Dengan demikian dapat diambil kesimpulan bahwa siswa yang mendapat skor $53-60$ mendapat nilai $10,48-52=9,43-47=8,38-42=7,33-37=6,28-32=5,23-27=4$, $18-22=3,13-17=2,8-12=1$, dan skor dibawahnya 0.

Bila kita ingin agar skala tersebut lebih halus yakni ada nilai diantara nilai-nilai tersebut, seperti 9,5; 8,5; 7,5 dan seterusnya, kita bisa memperkecil jarak antar skala-skala itu. Diantara 2,25 (SD) dan 1,75 (SD) dapat ditempatkan 2,00 (SD) yang ekuivalen dengan nilai 9,5. Diantara 1,75 (SD) dan 1,25 (SD) dapat ditempatkan 1,50 (SD) yang ekuivalen dengan nilai 8,5 dan begitu seterusnya.

c. Pengolahan skor mentah menjadi skor standar Z dan $\mathrm{T}$

Pengolahan skor mentah menjadi skor Z ini sering kali dirasakan perlunya karena dengan hanya melihat skor mentah saja kita belum dapat memberikan tafsiran yang baik dan tepat. Dengan menggunakan rata-rata dan SD kita dapat menjabarkan atau mengubah skor-skor yang diperoleh menjadi skor $\mathrm{Z}$ dengan menggunakan rumus dibawah ini.

$\mathrm{Z}=0,5$

$\mathrm{X}=$ skor mentah yang diperoleh siswa.

Sedangkan T- Score disebut juga skala 0-100. Rumus T- Score adalah:

$\mathrm{T}=($ ) $10+50=30$ 


\section{Penilaian Acuan Norma (PAN)}

Penilaian acuan norma menskor peserta didik dengan membandingkan hasil belajar satu peserta dengan hasil peserta lainnya dalam satu kelompok kelas. Contoh diketahui 20 siswa mengikuti ujian akhir semester mata pelajaran bahasa Arab memperoleh skor mentah sebagai berikut:

$32, \quad 36, \quad 27, \quad 50, \quad 22$,

$34, \quad 35, \quad 37, \quad 43, \quad 17$,

$21, \quad 42, \quad 46, \quad 32, \quad 31$,

$28, \quad 57, \quad 57, \quad 54, \quad 51$.

Penyelesaian nilai peserta didik dengan pendekatan PAN:

a. Menyusun skor terkecil hingga terbesar

$17, \quad 21, \quad 22, \quad 27, \quad 28$,

$31, \quad 32, \quad 32, \quad 34, \quad 35$,

$36, \quad 37, \quad 42, \quad 43, \quad 46$,

$50, \quad 51, \quad 54, \quad 57, \quad 57$.

(1) Mencari rentangan (range) yaitu skor terbesar dikurangi skor terkecil

$57-17=40$

(2) Mencari banyak kelas interval

$$
\begin{aligned}
\text { Banyak kelas } & \quad=1+(3,3) \log \mathrm{n} \\
= & 1+(3,3) \log 20 \\
= & 1+(3,3)(1,3010) \\
= & 1+4,2933=5,2933 \\
= & 6 \text { (dibulatkan) }
\end{aligned}
$$

(3) Mencari interval kelas

Interval $=6,666=7$ (dibulatkan)

(4) Menyusun daftar distribusi frekuensi

$\begin{array}{lll}\text { Kelas interval } & \text { Tabulasi } & \text { Frekuensi } \\ 52-58 & \text { III } & 3 \\ 45-51 & \text { III } & 3 \\ 38-44 & \text { II } & 2 \\ 31-37 & \text { IIIIII } & 7 \\ 24-30 & \text { II } & 2 \\ 17-23 & \text { III } & 3 \\ \text { Jumlah } & & 20\end{array}$


b. Menghitung rata-rata actual

\begin{tabular}{|c|c|c|c|c|}
\hline Interval Kelas & Frekuensi (f) & Nilai Tengah (Nt) & (f.Nt) & (f.Nt) \\
\hline $52-58$ & 3 & 55 & 165 & 9.075 \\
\hline $45-51$ & 3 & 48 & 144 & 6.912 \\
\hline $38-44$ & 2 & 41 & 82 & 3.362 \\
\hline $31-37$ & 7 & 34 & 238 & 8.092 \\
\hline $24-30$ & 2 & 27 & 54 & 1.458 \\
\hline $17-23$ & 3 & 20 & 60 & 1.200 \\
\hline Jumlah & & & 743 & 30.099 \\
\hline
\end{tabular}

Rumus rata-rata actual[10]

$=\quad=\quad=37.15$

c. Menghitung simpangan baku aktual

$$
\begin{aligned}
& \mathrm{SD}== \\
& =\quad=11.46
\end{aligned}
$$

d. Menyusun pedoman konversi

Pedoman konversi yang digunakan sama dengan PAP, hanya berbeda pada penghitungan rata-rata () dan simpangan baku (SD).

\section{Merangking Siswa dari Beberapa Mata Pelajaran}

Dibawah ini terdapat 5 siswa yang mempunyai variasi skor yang unik. Hanya dengan melihat jumlah skor saja dapatkah ditentukan siapa yang menduduki tempat tertinggi?[12]

\begin{tabular}{|l|c|c|c|c|c|c|c|}
\hline $\begin{array}{l}\text { Bidang Studi } \\
\text { Nama }\end{array}$ & MTK & IPA & IPS & B.INDO & B.ARAB & Jumlah & No. \\
\hline Tina & 90 & 90 & 90 & 90 & 90 & 253 & I \\
\hline Rita & 70 & 70 & 70 & 70 & 70 & 251 & II \\
\hline Haya & 50 & 50 & 50 & 50 & 50 & 250 & III \\
\hline Dita & 30 & 30 & 30 & 30 & 30 & 249 & IV \\
\hline Alia & 10 & 10 & 10 & 10 & 10 & 247 & V \\
\hline MEAN & $\mathbf{5 0}$ & $\mathbf{5 0}$ & $\mathbf{5 0}$ & $\mathbf{5 0}$ & $\mathbf{5 0}$ & & \\
\hline S.DEVIASI & $\mathbf{3 1 . 8 4}$ & $\mathbf{1 4 . 1 4}$ & $\mathbf{7 . 0 7}$ & $\mathbf{3 . 6 9}$ & $\mathbf{1 . 4 1}$ & & \\
\hline
\end{tabular}

Mean $=$

$\mathrm{SD}=$ 
Melihat keadaan nilai kelima siswa tersebut, nampaknya Tina menduduki peringkat teratas karena memiliki jumlah skor terbanyak. Sedangkan Ani memiliki skor paling sedikit sehingga menduduki peringkat paling bawah. Apakah ketentuan ini adil?. Dengan menggunakan Z- score dapat lain bahkan menjadi sebaliknya.

Contoh nilai MTK Tina adalah 90. Rata-rata nilai matematika tersebut adalah 50 dengan standar deviasi 31.84. Maka Z-score Tini adalah:

$$
\mathrm{Z}=\mathbf{=} 1,26
$$

Dengan cara yang sama akan dapat dicari Z-score masing-masing siswa untuk seluruh bidang studi. Dan hasilnya sebagai berikut:

\begin{tabular}{|l|c|c|c|c|c|c|c|}
\hline $\begin{array}{l}\text { Studi } \\
\text { Nama }\end{array}$ & MTK & IPA & IPS & B.IND & B.ARAB & Jumlah & No \\
\hline Tina & 1.26 & -1.41 & -1.41 & -1.36 & -1.42 & -4.34 & V \\
\hline Rita & 0.63 & -0.71 & -0.71 & -0.81 & -0.71 & -2.31 & IV \\
\hline Haya & 0.00 & -0.00 & -0.00 & -0.00 & -0.00 & -0.00 & III \\
\hline Dita & 0.63 & 0.71 & 0.71 & 0.81 & 0.71 & 2.31 & II \\
\hline Alia & 1.26 & 1.41 & 1.41 & 1.36 & 1.42 & 4.34 & I \\
\hline
\end{tabular}

\section{KESIMPULAN}

Berdasarkan dari penjelasan di atas maka kami selaku penulis artikel ini memberikan kesimpulan sebagai berikut:

1. Teknik Pengolahan Data Hasil Evaluasi dengan cara diantaranya sebagai berikut:

a. Mengolah skor mentah menjadi nilai huruf

b. Mengolah skor mentah menjadi skor standart 1-10

c. Mengolah skor mentah menjadi skor standart Z dan T

2. Pedoman konversi yang digunakan PAP dan PAN sama, hanya berbeda pada penghitungan rata-rata () dan simpangan baku (SD).

3. Dalam memberikan peringkat siswa, menggunakan prosedur z-score akan lebih evektif dan jauh dari kemungkinan terjadinya ketidak adilan dibandingkan dengan memberikan peringkat dengan menjumlah skor keseluruhan saja. 


\section{Daftar Pustaka}

Janna, N. M., A., kurnia, A. d., \& Arsyam, M. (2021, January 14). Administrasi Keuangan Dalam Pendidikan. https://doi.org/10.31219/osf.io/hmvcf

Arsi, A., I., \& Arsyam, M. (2021, January 16). Artikel Administrasi Tata Kelola Dalam Pendidikan. https://doi.org/10.31219/osf.io/wsd9r

Arifin, Zainal. (2009). Evaluasi Pembelajaran. Bandung: PT Remaja Rosdakarya.

Arsyam, M., \& Alwi, A. M. (2020). MANAJEMEN HIDUP DALAM PERSPEKTIF AL-QUR'AN.

Arikunto, Suharsimi. (1996). Dasar-Dasar Evaluasi Pendidikan. Jakarta: Bumi Aksara.

Makmur, Z., Arsyam, M., \& Alwi, A. M. S. (2020). Strategi Komunikasi Pembelajaran Di Rumah Dalam Lingkungan Keluarga Masa Pandemi. KOMUNIDA: Media Komunikasi dan Dakwah, 10(02), 231-241.

Baharun, H. (2016). Penilaian Berbasis Kelas pada Pembelajaran Pendidikan Agama Islam di Madrasah. MODELING: Jurnal Program Studi PGMI, 3(2), 204-216.

Mudjijo. (1995). Tes Hasil Belajar. Jakarta: Bumi Aksara.

Arsyam, M. (2020). Manajemen pendidikan islam.

Ependi, U., Putra, A., \& Panjaitan, F. (2019). Evaluasi tingkat kebergunaan aplikasi Administrasi Penduduk menggunakan teknik System Usability Scale. Register: Jurnal Ilmiah Teknologi Sistem Informasi, 5(1), 63-76.

Arsyam, M. (2021). BAHAN AJAR ADMINISTRASI PENDIDIKAN.

Astuti, S. (2016). Penerapan supervisi akademik untuk meningkatkan kompetensi guru dalam menyusun administrasi penilaian di sd laboratorium uksw. Scholaria: Jurnal Pendidikan dan Kebudayaan, 6(1), 117-126.

WEKKE, I. S. EVALUASI PENGEMBANGAN KURIKULUM MADRASAH MINORITAS MUSLIM: TINJAUAN DARI PAPUA BARAT.

Muslim, A. Q., \& Wekke, I. S. (2018). Model Penilaian Kinerja Guru. Al-TA'DIB: Jurnal Kajian Ilmu Kependidikan, 11(1), 37-54.

Purwanto, Ngalim. (2006). Prinsip-prinsip dan Teknik Evaluasi Pengajaran. Bandung: PT Remaja Rosdakarya. 